Al-Madrasah: Jurnal Ilmiah Pendidikan Madrasah Ibtidaiyah

Vol. 5, No. 1, 2020

DOI 10.35931/am.v5i1.394

P-ISSN: 2620-5807; E-ISSN: 2620-7184

\title{
IMPLEMENTASI PENDIDIKAN MULTIKULTURAL MELALUI MEDIA POP UP BOOK TEMATIK DI SEKOLAH DASAR
}

\author{
Ricka Tesi Muskania*1, Arita Marini' ${ }^{2}$, Arifin Maksum ${ }^{3}$ \\ ${ }^{1}$ Dosen, IAIN Pontianak; Kalimantan Barat, Indonesia \\ ${ }^{2,3}$ Dosen, UNJ; Jakarta, Indonesia
}

e-mail: $\underline{\text { ricka.muskania@gmail.com, }}{ }^{2}$ aritamarini@unj.ac.id, ${ }^{3}$ amaksum@unj.ac.id

\begin{abstract}
Abstrak
Pendidikan multikultural memberikan kesempatan yang sama bagi peserta didik untuk dapat memiliki segala interaksi dari berbagai latar belakang budaya yang berbeda. Hal ini akan membentuk generasi Indonesia menjadi unggul dan membanggakan yang menjadikan keanekaragaman sebagai kekayaan yang mempersatukan bangsa Indonesia. Dalam pendidikan tematik guru harus dapat mengintegrasikan beberapa materi dalam suatu tema dengan merangkul peserta didik dalam proses pembelajarannya sehingga peserta didik menikmati proses pembelajaran yang berlangsung tanpa deskriminasi terhadap kelompok minoritas. Penelitian ini merupakan penelitian kualitatof dengan rancangan studi kasus. Data diperoleh melalui wawancara dan observasi langsung selama proses pembelajaran berlangsung. Sumber data dalam penelitian ini adalah guru kelas VI di Madrasah Ibtidaiyah. Tema yang diamati adalah rukun dalam perbedaan. Hasil dari penelitian ini memberikan gambaran pelaksanaan pembelajaran tematik yang dapat dilaksanakan berbasis multikultural dengan media pop up book karena di usia sekolah dasar perlu penanaman nilai-nilai toleransi dan saling menghargai terhadap perbedaan. Kesadaran akan keanekaragaman budaya Indonesia akan membentuk generasi masa depan yang tidak sekedar menguasai teknologi tapi juga paham akan pentingnya keberagaman budaya, suku, bahasa, dan agama di Indonesia sebagai pemersatu yang disimbolkan dengan istilah bhineka tunggal ika.
\end{abstract}

Kata kunci: Pendidikan multikultural, pembelajaran tematik, pop up book)

\section{PENDAHULUAN}

【ndonesia merupakan negara yang beranekaragam dengan populasi lebih dari dua ratus juta jiwa. Bentuk negara kepulauan menjadikan Indonesia menjadi kaya akan suku, budaya, bahasa, agama, adat istiadat dan berbagai hal lainnya sehingga wajarlah semboyan dari negara Indonesia adalah Bhineka Tunggal Ika yang berarti berbeda-beda tetap satu 
jua. Keanekaragaman ini mengharuskan pendidikan di Indonesia berbasis pendidikan multikultural yang menanamkan nilai-nilai persatuan dalam perbedaan agar setiap orang dapat saling menghormati dan menghargai serta dapat bertoleransi terhadap perbedaan yang dalam kehidupan bermasyarakat. Tokoh Abdurahman Wahid atau lebih familiar dengan panggilan Gus Dur merupakan pelopor konsep multikultural pertama di Indonesia yang memberikan gambaran kemajemukan kehidupan berbangsa dan bernegara. Hingga saat ini begitu banyak konfilik yang muncul atas dasar perbedaan yang ada di negara Indonesia.

Konflik terbesar yang pernah muncul yang disebabkan karena perbedaan etnis adalah yang terjadi pada tahun 90an di provinsi Kalimantan Barat. Selain itu, juga ada beberapa konflik yang muncul disebabkan perbedaan agama. Hal ini jelas memperlihatkan bahwa perubahan zaman menyebabkan pola pikir manusia dalam memecahkan masalah melalui kekerasan dengan memunculkan latar belakang suku ataupun agama.

Pendidikan multikultural merupakan pendidikan yang dapat membina sikap peserta didik untuk menghargai keragaman budaya masyarakat, pendidikan ini juga menawarkan beragam model dalam upaya perdamaian di Indonesia ${ }^{1}$. Definisi ini menjelaskan bahwa tujuan dari pendidikan multikultural berkaitan dengan sikap, pengetahuan, dan pembelajaran.

Usia peserta didik pada sekolah dasar secara umum belajar dari segala

sesuatu yang bersifat konkret atau nyata serta memahami sesuatu secara holistik dan menyeluruh sehingga pada jenjang Sekolah Dasar diperlukan pembelajaran tematik yang menggunakan satu tema dengan konsep yang saling berkaitan agar mudah dipahami oleh peserta didik. Tema tersebut pun harus dekat dengan kehidupan peserta didik. Konsep yang dapat dipelajari oleh peserta didik sekolah dasar adalah konsep sederhana dan dekat

\footnotetext{
${ }^{1}$ Nurul Afifah. Implementasi Pembelajaran Berbasis Multikultur dan Budaya di SD / MI, Ar-Riyah: Jurnal Pendidikan Dasar, (2017), 1(01).
}

Al-Madrasah: Jurnal Ilmiah Pendidikan Madrasah Ibtidaiyah Vol. 5, No. 1, Juli-Desember 2020 
Ricka Tesi Muskania, Arita Marini, Arifin Maksum : Implementasi Pendidikan Multikultural Melalui Media POP UP BOOK Tematik di Sekolah Dasar

dengan kehidupan sehari-hari mereka sehingga perlu dilakukan penelitian lebih lanjut tentang proses pembelajaran tematik menggunakan media Pop Up Book berbasis pendidikan multikultural pada jenjang sekolah dasar.

Beberapa penelitian terdahulu yang ditemukan oleh peneliti diantaranya adalah ebook tematik terpadu berbasis multikultural dalam kegiatan School from $\mathrm{Home}^{2}$, pendidikan multikultural berbantual metode Pictorial untuk meningkatkan karakter kreatif dan bersahabat kelas 3 Sekolah Dasar $^{3}$, dan implementasi pembelajaran berbasis multikultur dan budaya di SD/MI ${ }^{4}$. Beberapa penelitian terdahulu tersebut belum ada yang meneliti bagaimana penggunaan media pop up book tematik berbasis pendidikan multikultural pada Sekolah Dasar.

\section{METODE PENELITIAN}

Pendekatan yang digunakan dalam penelitian ini adalah pendekatan kualitatif dengan penelitian studi kasus. Pengumpulan data melalui wawancara dan observasi selama proses pembelajaran tematik. Wawancara dilakukan untuk mengetahui konsep pendidikan multikultural yang dirancang guru dalam media pop up book tematik yang akan digunakan dalam proses pembelajaran, sedangkan observasi dilakukan untuk mengumpulkan bagaimana penerapan pembelajaran tematik berbasis pendidikan multikultural melalui media pop up book pada tema rukun dalam perbedaan. Sampel yang digunakan adalah purposive sampling berdasarkan kriteria yang telah ditetapkan oleh peneliti. Subjek

${ }^{2}$ Fernindia Eva Sabtaningrum, Iskandar Wiyokusumo., \& Ibut Priono Leksono, E-book Tematik Terpadu Berbasis Multikultural Dalam Kegiatan SFH (School from Home). Jurnal Ilmiah Sekolah Dasar, (2020), 4(2), 153.

${ }^{3}$ Ika Ari Pratiwi, Siti Masfuah, \& Wawan Shokib, Pendidikan Multikultural Berbantuan Metode Pictorial Riddle Untuk Meningkatkan Karakter Kreatif dan Bersahabat Siswa Kelas 3 Sekolah Dasar. Scholaria: Jurnal Pendidikan Dan Kebudayaan, (2018), 8(2), 109-119.

${ }^{4}$ Nurul Afifah. Implementasi Pembelajaran Berbasis Multikultur dan Budaya di SD / MI, Ar-Riyah: Jurnal Pendidikan Dasar, (2017), 1(01).

Al-Madrasah: Jurnal Ilmiah Pendidikan Madrasah Ibtidaiyah Vol. 5, No. 1, Juli-Desember 2020 
Ricka Tesi Muskania, Arita Marini, Arifin Maksum : Implementasi Pendidikan Multikultural Melalui Media POP UP BOOK Tematik di Sekolah Dasar

penelitian adalah guru kelas VI Madrasah Ibtidaiyah. Dianalisis menggunakan Nvivo 8 yang diturunkan dari hasil wawancara dan data observasi.

\section{HASIL DAN PEMBAHASAN}

Implementasi pendidikan multikultural dalam kurikulum dan pembelajaran masih terbatas di sekolah dasar ${ }^{5}$. Lebih lanjut terkait implikasi kurikulum berbasis multikultural hanya sebatas kognitif saja sedangkn dua aspek lain yaitu afektif dan psikomotor ${ }^{6}$. Pengetahuan guru tentang pendidikan multikultural juga belum sepenuhnya. Sebagai seorang guru terutama di sekolah dasar, guru harus memahami peran budaya di kelas dan menerapkan praktik pengajaran yang mengakomodasi siswa dari latar belakang budaya yang beragam ${ }^{7}$.

\section{Konten Media Pop Up Book Tematik}

Pembelajaran tematik merupakan pembelajaran yang mengintegrasikan beberapa mata pelajaran dalam tema tertentu. Media Pop Up Book tematik merupakan media pembelajaran yang dikembangkan untuk membantu peserta didik memahami dan bertoleransi terhadap perbedaan suku, agama, budaya, bahasa, dan adat istiadat di Kalimantan Barat. Media ini dibentuk dari tema "Rukun dalam Perbedaan". Tema tersebut jelas memberikan makna pendidikan multikultural yang dalam. Media Pop Up Book tematik dirancang dengan berbagai gambar yang menampilkan keanekaragaman suku dan agama yang ada di tanah borneo. Tampilan animasi yang dimunculkan dalam media juga merupakan benar-benar hasil editing dari gambar yang diambil secara langsung.

5 Sutjipto Sutjipto, Udi Budi Wibowo, \& Arum Dwi Hastutiningsih, Implementasi Kurikulum Multikultural Di Sekolah Dasar. Jurnal Pendidikan Dan Kebudayaan, (2017), 2(1).

6 Moh. Irmawan Jauhari, Taksonomi Bloom Implementasi Kurikulum Berbasis Multikultural. Journal of Applied Linguistics and Islamic Education, (2017), 14 (1)., 55-64.

7 Emily Aragona-Young, \& Brook E Sawyer, Elementary teachers' beliefs about multicultural education practices, Teachers and Teaching, (2018), 24(5), 465-486.

Al-Madrasah: Jurnal Ilmiah Pendidikan Madrasah Ibtidaiyah Vol. 5, No. 1, Juli-Desember 2020 
Ricka Tesi Muskania, Arita Marini, Arifin Maksum : Implementasi Pendidikan Multikultural Melalui Media POP UP BOOK Tematik di Sekolah Dasar

Halaman pertama media ini berisi informasi terkait keterpaduan Kompetensi Dasar dari beberapa mata pelajaran. Ada tiga mata pelajaran yang tergabung yaitu Ilmu Pengetahuan Sosial, Bahasa Indonesia, dan Seni Budaya dan Prakarya. Kompetensi Dasar ditampilkan dalam bentuk peta konsep.

Halaman kedua berisi pengenalan empat suku mayoritas yang ada di provinsi Kalimantan Barat. Suku ini terdiri dari suku dayak, melayu, cina, dan madura. Tokoh yang ditampilkan adalah animasi dengan menggunakan pakaian khas masing-masing suku. Pengenalan tokoh ini menjadi pengantar dalm buku Pop Up Book berbasis pendidikan multikultural.

Pada halaman berikutnya ditampilkan gambar dengan tampilan $180^{\circ}$. Gambar yang ditampilkan adalah gambar tempat beribadah yang mewakili perbedaan agama yang ada di Kalimantan Barat mulai dari Masjid Mujahidin, Vihara, Gereja, Pura, dan klenteng cina. Gambar asli tempat ibadah yang ada di Kalimantan Barat ini dirubah dalam bentuk animasi sehingga lebih menarik bagi peserta didik sekolah dasar.

Selain itu pada halaman berikutnya juga ditampilkan peringatan hari Ulang Tahun Kota Pontianak yang diperingati pada tanggal 23 Oktober dengan tampilan foto bersama saat kirab budaya. Foto tersebut menunjukkan besarnya toleransi masyarakat Pontianak dengan perbedaan suku dan agama.

Pada gambar juga dimunculkan sejarah konflik masyarakat melayu Sambas dan suku madura. Konflik ini sangat dikenal bahkan di dunia Internasional sehingga orang kalimantan dikenal dengan warga yang makan manusia. Label buruk ini memberikan kesan yang sangat tidak baik bagi masyarakat kalimantan. Tragedi ini dimunculkan untuk mengingatkan peserta didik bahwa diperlukannya tolerasi, rasa saling menghargai dan menghormati atas dasar perbedaan apapun sehingga kehidupan dapat terjali harmonis di masyarakat khususnya di Kalimantan Barat. Nilai persaudaraan dan persatuan sesama

Al-Madrasah: Jurnal Ilmiah Pendidikan Madrasah Ibtidaiyah Vol. 5, No. 1, Juli-Desember 2020 
suku/tenis menjadi nilai mutlak yang mengharuskan masyarakat untuk mampu beradaptasi dengan keanekaragaman yang ada ${ }^{8}$.

Pada media Pop Up Book juga ditampilkan tugu ketupat berdarah. Tugu ini dibangun untuk mengenang tragedi konflik antar suku yang pernah terjadi pada saat hari raya idul fitri. Tugu ini terletak di Kabupaten Sambas, Kalimantan Barat yang merupakan kabupaten asal terjadinya konflik yang telah dikenal dunia hingga saat ini.

Dari segi agama juga dimunculkan pelaksanaan idul adha dengan memotong hewan qurban yang hasil pemotongan hewan qurban dappat diberikan kepada siapapun tanpa melihat perbedaan agama. Hal ini diperjelas pula oleh Suharto bahwa Orang Islam di Indonesia adalah Islam dengan senyuman di wajah yang penuh dengan kedamaian.

\section{Proses Pembelajaran Tematik dengan Pop Up Book berbasis pendidikan multikultural}

Pelaksanaan pembelajaran tematik menggunakan media Pop Up Book berbasis pendidikan multikultural sama seperti pembelajaran tematik lainnya. Hanya saja penggunaan media ini sangat berperan dalam membentuk sikap toleransi terhadap keanekaragaman suku, agama dan perbedaan lain yang ada di provinsi Kalimantan Barat. Kegiatan appersepsi dilakukan dengan mengelompokkan peserta didik berdasarkan suku. Setelah itu, dibentuk lagi berdasarkan agama sehingga terbentuk banyak kelompok yang kemudian akan menganggap dirinya merasa paling baik diantara yang lain. Masing-masing kelompok diminta untuk melakukan penilaian terhadap kelompoknya dan kelompok lain untuk mengetahui konsep awal tentang pendidikan multikultural yang dimiliki oleh peserta didik.

8 Atik Wartini, Pendidikan Multikultural Berbasis Karakter Keindonesiaan Pada Pendidikan Anak Usia Dini Upaya Integrasi Ilmu Ke-Islaman Dan Karakter Kebudayaan Indonesia (Studi Kasus di Sanggar Anak Alam Yogyakarta). Toleransi, (2015)., 7(1), 41-60.

9 Toto Suharto, Gagasan Pendidikan Muhammadiyah dan NU Sebagai Potret Pendidikan Islam Moderat di Indonesia, ISLAMICA: Jurnal Studi Islam,(2014), 9(1), 1-43.

Al-Madrasah: Jurnal Ilmiah Pendidikan Madrasah Ibtidaiyah Vol. 5, No. 1, Juli-Desember 2020 
Ricka Tesi Muskania, Arita Marini, Arifin Maksum : Implementasi Pendidikan Multikultural Melalui Media POP UP BOOK Tematik di Sekolah Dasar

Kegiatan berikutnya peserta didik diajak bersama-sama menemukan tema yang akan dipelajari dan memunculkan rasa ingin tahu yang tinggi dengan menampilkan buku Pop Up Book tematik di depan kelas. Setiap kelompok memiliki satu media Pop Up Book tematik yang kemudian diminta untuk mengamati dan mencermati isi dari media.

Peserta didik menunjukkan antusias yang sangat tinggi dengan media tersebut karena guru lain belum pernah menggunakan media seperti ini dengan menampilkan budaya dan suku yang ada di provinsi Kalimantan Barat secara visual dalam bentuk gambar. Media ini seakan membawa peserta didik berada pada lokasi yang sebenarnya tanpa harus turun ke lokasi.

Kegiatan berikutnya peserta didik diminta untuk membuat karangan khusus tentang tema yang dipelajari. Mengidentifikasi hal-hal positif yang boleh dilakukan dan hal-hal negatif yang tidak boleh dilakukan atas dasar perbedaan tersebut dalam kehidupan bermasyarakat terutama di lingkungan sekolah. Pembelajaran tematik berbasis multikultural seperti ini wajib dilestarikan dan diteruskan dengan perubahan yang semakin baik dari masa ke masa karena pembelajaran ini secara langsung maupun tidak langsung akan membentuk rasa nasionalisme ${ }^{10}$. Hal yang paling penting dan mendasar untuk diajarkan pada peserta didik adalah pemahaman tetang keragaman yang merupakan modal pembangunan ${ }^{11}$. Tampilan dari pendidikan multikultural adalah keahlian untuk menguasai dan membangun kesadaran budaya ${ }^{12}$.

${ }^{10}$ Susi Setyowati, Yusinta Dwi Ariyani, \& Ruwet Rusiyono, Pengembangan Bahan Ajar Pendidikan Multikultural Berbasis Karakter Nasionalisme Pada Pembelajaran Tematik Kelas IV SD Negeri Trucuk Bantul, Elementary School Journal, (2019), 3(5), 113-124.

${ }^{11}$ Laila Fatmawati, Rani Dita Pratiwi, \& Vera Yuli Erviana, Pengembangan Modul Pendidikan Multikultural Berbasis Karakter Cinta Tanah Air dan Nasionalis pada Pembelajaran Tematik, Scholaria: Jurnal Pendidikan dan Kebudayaan, (2018), 8(1), 80-92.

${ }_{12}$ Subandi Subandi, Ahmad Fauzan, Muhammad Muchsin Afriyadi, Mispani Ramli, Implementation of Multicultural and Moderate Islamic Education at the Elementary Schools in Shaping the Nationalism, Tadris: Jurnal Keguruan dan Ilmu Tarbiyah, (2019), 4(2), 247-255.

Al-Madrasah: Jurnal Ilmiah Pendidikan Madrasah Ibtidaiyah Vol. 5, No. 1, Juli-Desember 2020 
Ricka Tesi Muskania, Arita Marini, Arifin Maksum : Implementasi Pendidikan Multikultural Melalui Media POP UP BOOK Tematik di Sekolah Dasar

\section{KESIMPULAN}

Media pop up book tematik yang digunakan berisi konten materi kelas VI di sekolah dasar dengan memadukan beberapa tampilan budaya yang ada di kalimantan barat. Penggunaan media pembelajaran pop up book juga dikolaborasikan dengan pendekatan dan strategi pembelajaran yang tepat untuk mendukung keberhasilan proses pembelajaran tematik berbasis pendidikan multikultural bagi anak-anak di sekolah dasar. Ini merupakan upaya agar dapat menghasilkan peserta didik yang memiliki nilai-nilai toleransi dalam kehidupan di masyarakat Indonesia yang memiliki berbagai suku, budaya, agama, dan adat istiadat. Pengembangan Bahan Ajar Pendidikan Multikultural Berbasis Karakter Nasionalisme Pada Pembelajaran Tematik Kelas IV SD Negeri Trucuk Bantul

\section{SARAN DAN REKOMENDASI}

Saran yang dapat diberikan peneliti terkait penelitian ini bahwa diperlukan penelitian lanjut yang melakukan uji coba pengaruh media pop up book dalam pembelajaran tematik terhadap kesadaran berbudaya peserta didik, sehingga dapat terlihat seberapa besar pengaruh media tersebut dalam peningkatan pengetahuan dan kesadaran berbudaya peserta didik di sekolah dasar.

\section{DAFTAR PUSTAKA}

Afifah, N. (2017). Implementasi Pembelajaran Berbasis Multikultur dan Budaya di SD / MI. ArRiyah: Jurnal Pendidikan Dasar, 1(01).

Aragona-Young, E., \& Sawyer, B. E. (2018). Elementary teachers' beliefs about multicultural education practices. Teachers and Teaching: Theory and Practice, 24(5), 465-486. https://doi.org/10.1080/13540602.2018.1435527

Fatmawati, L., Pratiwi, R. D., \& Erviana, V. Y. (2018). Pengembangan Modul Pendidikan Multikultural Berbasis Karakter Cinta Tanah Air dan Nasionalis pada Pembelajaran Tematik. Scholaria: Jurnal Pendidikan Dan Kebudayaan, 8(1), 80-92. https://doi.org/10.24246/j.js.2018.v8.i1.p80-92

Jauhari, M. I. (2017). Taksonomi Bloom dan Implementasi Kurikulum Berbasis Multikultural. $14(1), 55-64$.

Al-Madrasah: Jurnal Ilmiah Pendidikan Madrasah Ibtidaiyah Vol. 5, No. 1, Juli-Desember 2020 
Pratiwi, I. A., Masfuah, S., \& Rondli, W. S. (2018). Pendidikan Multikultural Berbantuan Metode Pictorial Riddle Untuk Meningkatkan Karakter Kreatif dan Bersahabat Siswa Kelas 3 Sekolah Dasar. Scholaria: Jurnal Pendidikan Dan Kebudayaan, 8(2), 109-119. https://doi.org/10.24246/j.js.2018.v8.i2.p109-119

Sabtaningrum, F. E., Wiyokusumo, I., \& Leksono, I. P. (2020). E-book Tematik Terpadu Berbasis Multikultural Dalam Kegiatan SFH (School from Home). Jurnal Ilmiah Sekolah Dasar, 4(2), 153. https://doi.org/10.23887/jisd.v4i2.24796

Setyowati, S., Ariyani, Y. D., \& Rusiyono, R. (2019). Pengembangan Bahan Ajar Pendidikan Multikultural Berbasis Karakter Nasionalisme Pada Pembelajaran Tematik Kelas IV SD Negeri Trucuk Bantul. Elementary School Journal, 3(5), 113-124.

Subandi, S., Fauzan, A., Afriyadi, M. M., \& Ramli, M. (2019). Implementation of Multicultural and Moderate Islamic Education at the Elementary Schools in Shaping the Nationalism. Tadris: Jurnal Keguruan Dan Ilmu Tarbiyah, 4(2), 247-255. https://doi.org/10.24042/tadris.v4i2.5003

Suharto, T. (2014). Gagasan Pendidikan Muhammadiyah dan NU Sebagai Potret Pendidikan Islam Moderat di Indonesia. ISLAMICA: Jurnal Studi Keislaman, 9(1), 1-43. http://dx.doi.org/10.1016/j.scitotenv.2014.10.007

Sutjipto, S., Wibowo, U. B., \& Hastutiningsih, A. D. (2017). Implementasi Kurikulum Multikultural Di Sekolah Dasar. Jurnal Pendidikan Dan Kebudayaan, 2(1), 1. https://doi.org/10.24832/jpnk.v2i1.618

Wartini, A. (2015). Pendidikan Multikultural Berbasis Karakter Keindonesiaan Pada Pendidikan Anak Usia Dini Upaya Integrasi Ilmu Ke-Islaman Dan Karakter Kebudayaan Indonesia (Studi Kasus di Sanggar Anak Alam Yogyakarta). Toleransi, 7(1), 41-60.

Al-Madrasah: Jurnal Ilmiah Pendidikan Madrasah Ibtidaiyah

Vol. 5, No. 1, Juli-Desember 2020 